obtained, and he gives the general series from which this value can be deduced. With its use, harmonic analysis with two arguments would give the coefficients of the needed periodic terms without the extensive numerical calculations which are usually necessary.

B. A. Bernstein, Secretary of the Section.

\title{
A CORRECTION
}

BY W. J. TRJITZINSKY

My attention has been drawn to the fact that Theorem I of my paper, Expansion in series of non-inverted factorials, (this Bulletin, vol. 34 (1928), pp. 193-196), is not new. This theorem is a special case of a theorem found on page 229 of N. E. Nörlund's Differenzenrechnung, and is due to Nörlund; it appeared first in Annales de l'Ecole Normale Supérieure ((3), vol. 39 (1922)). The theorem is also a special case of a theorem less general than that of Nörlund, which was proved by Carlson in. Nova Acta Soc. Scient. Upsaliensis ((4), vol. 4 (1915)). Neither of these was known to me at the time of the publication of my paper. 